which has been described as forming part of the upper boundary of the right ventricle; and the same reasoning would apply to inefficient systole of the left ventricle. On anatomical grounds it may therefore be said that the aortic second sourd commands three cavities (the pulmonary artery through its right branch influencing only the left auricle) in addition to holding the high road for vibrations along the septum, and to practically exclujing the pulmonary sound

Fig. $4 .^{1}$

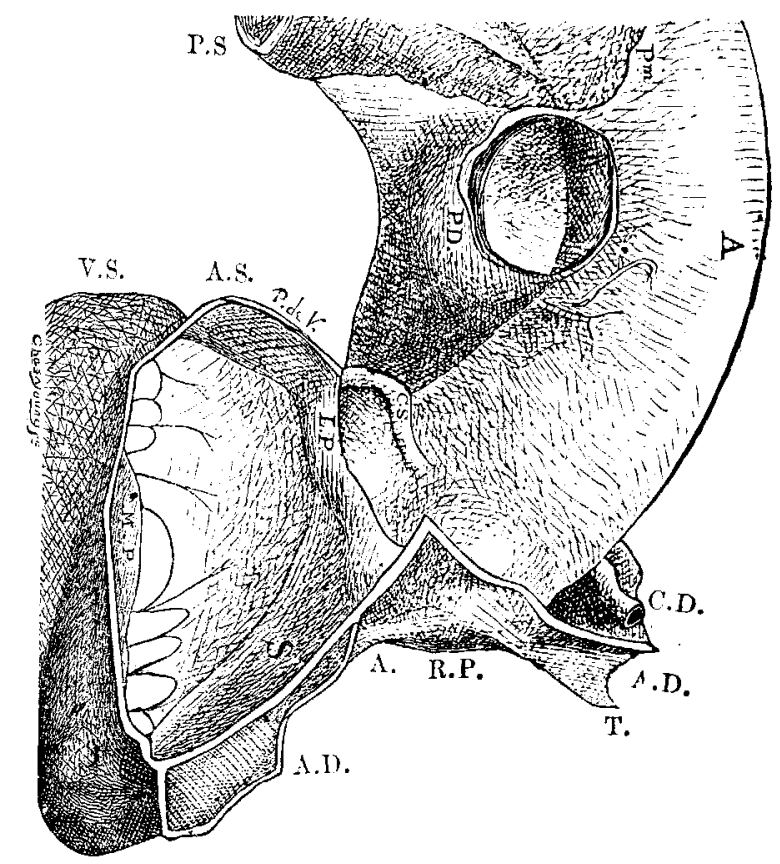

Same preparation as in Fig. 3, riewed from liehind, from above, and from the right. A. : 'lihe aorta. P. 1). sicction through the right branch of the pulmonary artery. $s$. : The auricular septum. A.D. : The right auricle. 1. s. : The let andicle ant the upper surface of the anterior mitral flap. M. P.: The posterior mitral flap. T.: The upper extremity of the upuer tricurpicl flap, continuous with the nembiane $(a)$ of the so-called undetended space. r.s.: The left rentricle, separated from the left anicle by the aurculo-ventricular groove. The other letter's as in Fig. 3.

from propagation into the right ventricle. For the pulmonary sound there remain only loud and direct conduction to the anterior chest-wall immediately covering the valve, as well as to a limited adjacent district, and inaudible conduction into the depth of the chest along the pulmonary artery and its branches.

\section{DIPHTHERIA TREATED BY ANTITOXIN.}

BY HUNTER URQUHART WALKER, L.R.C.P. \& S. EDIN., LATE MEDICAI OFFICER OF HEAITH, WORKSOP, NOTTS.

THE present seems to me to be a favourable time to publish in the columns of THE LANCET a few remarks that I consider appropriate on the above subjtct, more especially as so much has been written in THE LAACET lately showing that cases of diphtheria are on the increase. Your readers doubtless have studied with interest the reports of cases of diphtheria which bave been treated in Guy's Hospital by Dr. Goodhart by means of antitoxin. I do not know that cases in private practice so treated have been mentioned in any journal. I was so struck with the results produced, or apparently produced, by this drug that I determined to investigate the matter, ard when I bad a chance put antitoxin to the test. So I procured from Messrs. Zimmerman and Co. a small quantity of Behring's solutions. It is impossible, $I$ know by sad experience, for the hardworked general practitioner to be thoroughly vered in the great army of new drugs that we bave in the market, and I may therefore be pardoned if I state here for the benefit of my readers one or two facts with regard to the drug in question. Antitoxin, I think, deserves special consideration from us, and I shall have attained my object if others will state in THE LANCET their experience of the drug, and say whether it does or does not bear out what has been said of the new I All figures kindly sketched by Mr. P. de Vaumas, Fig. 1 and Fig. 2
reproduced from "Cardiac Outlines," Bulllière, 'lindall, and Cox, 1892. specific. With regard to Bchring's solution, it has been proved that if a mixture of 0.001 c.c. with the same amount of poison is subcutaneously administered to guinea-pigs, not only are no symptoms of dises se caused, hut also no local symptcms are observable, expecially no infiltration at the place of injection. The antitoxin solution contains 2 to 2.5 per cent. egg albumen and a further admixture of 0.4 per cent. trikresol for preservation purposes. For the immunisation of adults and elder children $1 \mathrm{c}$. c. of the eolution is injected subcutaneously by means of a Pravaz syringe, which has been previously sterilised by alcohol and three per cent. carbolic acid or one per cent. trikresol solution. For young children up to two years the dose should be 0.55 c.c. The above quantity of antitoxin thus administered to persons threatened by diphtheria is at least ten times as much as is required to render them immune. The immunity from diphtheria is therefore much more lasting. Before stating the particulars of the case in which I tried antitoxin I should like here to tender my best tharks to my partner, Dr. Crawford, to Dr. Hore, medical officer of Liverpool, and to Dr. Davidson, the bon. physician to the Liverpool Infirmary for Children, who kindly saw the case with me and interested themselves in the treatment of it.

I was called in to see the patient, eight years of age, on July 27th. I was told she had been ill for a day or two. She had passed a very restless night. On the 28th the child seemed more restless, the colour in the face was rather darker in bue, the pulse quicker and the breathirg more difficult. The thrcat presented much the same appearance as on the previous day. On the 29th the child was distinctly worse, especially the breathing. The fauces on the right and left side were covered with membrane. In the evening the respiration was very quick. On the 30th the membrane was well formed, even extending well over the soft palate and hanging down into the mouth. Up to this time the child had been treated with iron and chlorate of potash internally, and the constant use of the lime-water spray. (One patient under my care just previously-a very bad one-did so remarkably well with the lime-water spray that I naturally did not wish to discard this method of treatment in favour of another of which I had little or no experience.) However, it was evident that somethirg more would require to be done if the patient was to improve, for I noticed that in spite of the treatment another patch of membrane had formed in front of the curtain which hung down from the soft palate. I resorted to antitoxin. Eleven minims of antitoxin were then injected into the forearm with strict antiseptic precantions. The temperature at the time of ix jection was $103^{\circ} \mathrm{F}$., and the palse 140 . In four hours after the injection the child was much improved. There was no fever and the pulse was quite quiet. She had a good right and had to be roused by the nurse to receive her nourishment, which throughout consisted of beef tea, chicken soup, brandy and milk, and wine whey. On the 31 st I noticed that the same improvement continued, although the membrane was still present. However, it was apparently loosening at the right side. My patient informed me that her tempenature was $98.4^{\circ} \mathrm{F}$, and I fourd she was neally correct, as it was normal. During the day much of the membrane came away. 'The last patch to form had disappeared. All that was to be seen was on the urula and on the left side. On Ang. 1st all signs of membrane had disappeared; the temperature was normal and the pulse good. The patient begged to be allowed to have her picture-books in bed. The throat caused her no pain. From that date uninterrupted recovery took place.

I wculd especially notice in this case that within a few hours the temperature was reduced four degrees and afterwards remained normal. The constitutional disturbance was at orce checked, although the membrane still remained on the uvala and left side of the throat. The new patch on the soft palate at once disappeared, and the appearance generally became more normal. The injection in this case, as in other cases where it has been used, was entirely innocuous, being followed by neither local nor general disturbance.

Worksop, Notts.

The inangural address of the Abernethian Society of St. Bartholomew's Hospital will be delivered by Sir James Paget on Thursday next, Oct. 11th, at 8 P.M., at the hospital. Sir James Paget's address is entitled "Scientific Study in the Practice of Medicine and Surgery," and the newly joined students at St. Bartholomew's Hospital are especially invited to attend. 